\title{
An Analysis of the Swiss Electric Vehicle Market
}

\author{
Stephanie Teufel*, Kirstin Stadelmann, Roger Neuhaus \\ International Institute of Management in Technology (iimt), University of Fribourg, Bd. de Perolles 90, 1700 Fribourg, Switzerland
}

\begin{abstract}
Alternative energy is a major topic in political debates and the media. The paradigm shift towards a more environmentally friendly world is already well established, and vehicles with high $\mathrm{CO}_{2}$ emissions are frowned upon. Despite the universally accepted fact that the environment must be protected with better technologies and a sense of responsibility, the amount of electric vehicles (EV) on Swiss streets remains very low.

In this paper, we analyze the Swiss market of EV in order to ascertain the interest in e-mobility to understand how the market is dealing with supply and demand. We provide a framework for the market and the potential customers of $\mathrm{EV}$ to determine precisely the exact segments to include in the research. The analysis provides information about the potential users of EV who took part in the market survey, their travelling habits, and their interests. In the second part, the results demonstrate the expectations concerning EV: recharge places, activation, and payment methods. With these results, potential manufacturers can discover whether building electric charging stations will be lucrative, where they should be located, and which functions the stations should perform so as to be competitive and well-accepted.
\end{abstract}

Keywords: Electric park system, electric vehicles, market analysis, charging station

\section{Motivation}

Time is rare and precious. A cheap and efficient approach is required to reach all the destinations in a short amount of time with the least amount of resources. In order to fulfill those needs, our private and business lives are shaped by a nearly unlimited mobility. Popular thought regarding mobility is changing. Electric vehicles (EV) are enjoying newfound prominence as a result of this thinking. An indication of this movement is big car companies' development of innovative, marketable EV. However, a major problem is that the infrastructure and technology for an effective and efficient usage is not yet completely and satisfactorily developed (cf. for example [1]).

After the atomic disaster in Fukushima of 2011, people have to consider if the need for additional electricity is the right approach for the future. Obviously, keywords such as efficiency of electricity and emobility became contradictory in the minds of certain researchers and politicians. This issue is strongly influenced by public debates, above all by those in the mass media [2]. Therefore, it is crucial to find out where the general public as well as the business community sees the future of EV.

Against this background, the project Electric Park System was launched in order to make electric mobility accessible to all [3]. A global solution will be developed to offer services and technologies allowing for an easy deployment of charging stations while guarantying a national accessibility. Needless to say, a detailed market analysis is a necessary supplement to the technological aspects of development.

The market analysis is required to determine the significance of e-mobility, how the market is dealing with supply and demand, and what the current and future technology standards are. The challenge of the survey is to create an overview of the current situation and, more importantly, to find out what steps should be taken. Thus, the following topics are highlighted: the market potential for EV in the eyes of private and business customers as well as car distributors; the potential of electric charging stations; and the requirements and needs for EV and electric charging stations. The core task is, on the one hand, to

* Manuscript received June 11, 2012; revised August 3, 2012.

Corresponding author: Tel.: +41 2630084 35; fax: +41 2630097 94; E-mail address: stephanie.teufel@unifr.ch. 
determine whether the public is interested and willing to buy EV, and on the other hand, to deliver useful information needed to build a proper infrastructure with widely-accepted electric charging stations.

\section{Definitions}

When referring to EV in this paper, we mean the whole of road vehicles using an electric motor for propulsion, powered by stored electricity (battery). We consider only pure EV; hybrids are not covered by our research. We distinguish three major types: electric cars (vehicles with four wheels), electric 2wheelers (motorcycles, scooters, etc.), and electric company cars and delivery vehicles (small trucks).

\section{Market and Customer Definition}

The first step of a successful market definition is to define a complete framework for the market. Firstly, we define the different classes of vehicles that are going to be analyzed. Secondly, we define the market area, and finally we categorize the potential customers.

\subsection{Vehicle categorization}

It is important to keep in mind that this study will provide information about a future potential market; hence, only vehicles which can be driven on public streets legally are evaluated. Although more categories of vehicles may be found in the market, we focus on the following categories:

- Private vehicles, i.e., vehicles that are registered to a private person, mainly electric cars (e.g., compact cars, sedans, SUVs) or two-wheelers.

- Business or commercial vehicles, i.e., vehicles that are registered to companies or organizations. This may refer to electric cars or two-wheelers. In terms of a commercial type of use, we consider only vehicles up to a maximum of 3.5 tons (electric vans, pick-ups, and the like).

\subsection{Market area categorization}

Determining the proper scope is essential for guiding professional research. If the geographic market is selected too broadly, the data needed in order to gain complete market knowledge will be immense and cost-ineffective. Yet, if the market is chosen too narrowly, potential customers and institutions will not be considered and could potentially be lost. Projected onto our own research, this means that the EU market as a whole would be too large, since the market is not heterogeneous and a large research team would be necessary in order to analyze this market in its entirety. So, we focus instead on the Swiss market, which has the ideal size and structure for our purposes due to the multi-lingual / multi-cultural situation.

Table 1. Swiss road vehicles [4].

\begin{tabular}{|l|l|l|l|}
\hline Year & $\mathbf{2 0 0 9}$ & $\mathbf{2 0 1 0}$ & $\mathbf{2 0 1 1}$ \\
\hline Automobiles & 4'009'602 & 4'075'825 & 4'163'003 \\
\hline Motorcycles & $642^{\prime} 777$ & $651^{\prime} 202$ & $665^{\prime} 870$ \\
\hline Vans \& trucks & 327'808 & $335^{\prime} 200$ & $348^{\prime} 553$ \\
\hline
\end{tabular}

Table 1 shows that the number of road vehicles in Switzerland is nearly stable. There is only a small increase in automobiles and motorcycles (4\%) as well as in transport vehicles (6\%) within this two year span (2009-2011).

\subsection{Customer categorization}

The public has been demonstrating a distinct attitude towards e-mobility and electric charging stations, and this attitude is vitally important to analyze. People are driving vehicles for different political, 
environmental, and personal reasons. Hence, they also want special attributes in the product that others would not necessarily need. The potential customers are divided into three main categories:

- Private customers - Switzerland has a population of about 8 million people; around $50 \%$ male and $50 \%$ female; about $60 \%$ between ages 20 and 64; about 63\% German-, 21\% French-, and nearly 7\% Italian-speaking; these customers have high educational levels with an average of 12 years of education and average monthly income of approximately 6,000 CHF (cf. [5], [6]).

- Business customers - there exist about 315,000 business companies in Switzerland: 97.6\% small businesses ( $1-49$ employees), 2\% medium businesses (50 - 249 employees), and only $0.4 \%$ large businesses (250 and more employees) [7].

- Car distributors - there exist no relevant Swiss car manufacturers, but 33 major import companies [8] and about 5'200 garages [9].

The three categories and their approaches are completely different. However, an adequate economic and demographic frame must nevertheless be created to optimally gather the best information available.

\section{Research Structure}

In the following section, we discuss the structure of our research.

\subsection{Data collection}

From a marketing point of view, we know that data can be collected either with primary or secondary research, or as a combination thereof where applicable [10]. We use secondary research in order to define an optimal framework of questionnaires (external information on e-mobility, environment, economy, etc.), and combine this with a primary approach in terms of qualitative interviews with a few select individuals. This provides us with a secure understanding as to how to set up the quantitative questions.

The research we focus on is executed quantitatively using an online survey which is possibly the most representative method. Private as well as most business participants of the survey were chosen randomly, while automobile distributor participants were chosen deliberately. For further details, see [11].

\subsection{Experimental design}

The created research structure consists of the following three groups of questionnaires, with each group available in German and French: private customers, business customers, and automobile distributors. These three groups were chosen since each represents a potential customer group. Private and business customers may have equal principals and knowledge about the technology and market for a decision. However, the business customer may have other requirements and factors informing his or her decision. An automobile distributor, contrarily, knows completely different aspects of EV and expects different returns in the future. Because of these differences, it was important to separate the questionnaires into three distinct parts.

\subsection{Data ascertainment}

The architecture of a survey must be made evident since different approaches have distinct advantages and disadvantages with consequences. Thus, the following information aids in understanding the results.

- Program - the questionaires were set up with the open source program LimeSurvey [12]. The results were analyzed with SPSS [13].

- Data source - the outline of the questions was based on secondary data and some qualitative interviews; the quantitative research delivers primary data.

- Time of ascertainment - the questionaires were online for 71 days (July 2011 till September 2011).

- Channels of distribution - direct emailing was used in addition to the basic channels (cf. Table 2). The additional channel response rates were: Private (19.7\%), Business (1.65\%), and Distributors (3.1\%). 
Table 2. Cannels of distribution.

\begin{tabular}{|c|c|c|c|}
\hline & Private & Business & Distributors \\
\hline Basic & \multicolumn{3}{|c|}{$\begin{array}{l}\text { iimt homepage: www.iimt.ch } \\
\text { OCN homepage: www.ocn.ch } \\
\text { TCS homepage: www.tcs.ch } \\
\text { Xing iimt alumni member page: www.xing.com }\end{array}$} \\
\hline Additional & 1000 emails & 2000 emails & 1000 emails \\
\hline
\end{tabular}

\section{Analysis and Results}

Fig. 1 shows the model of the overall analysis.

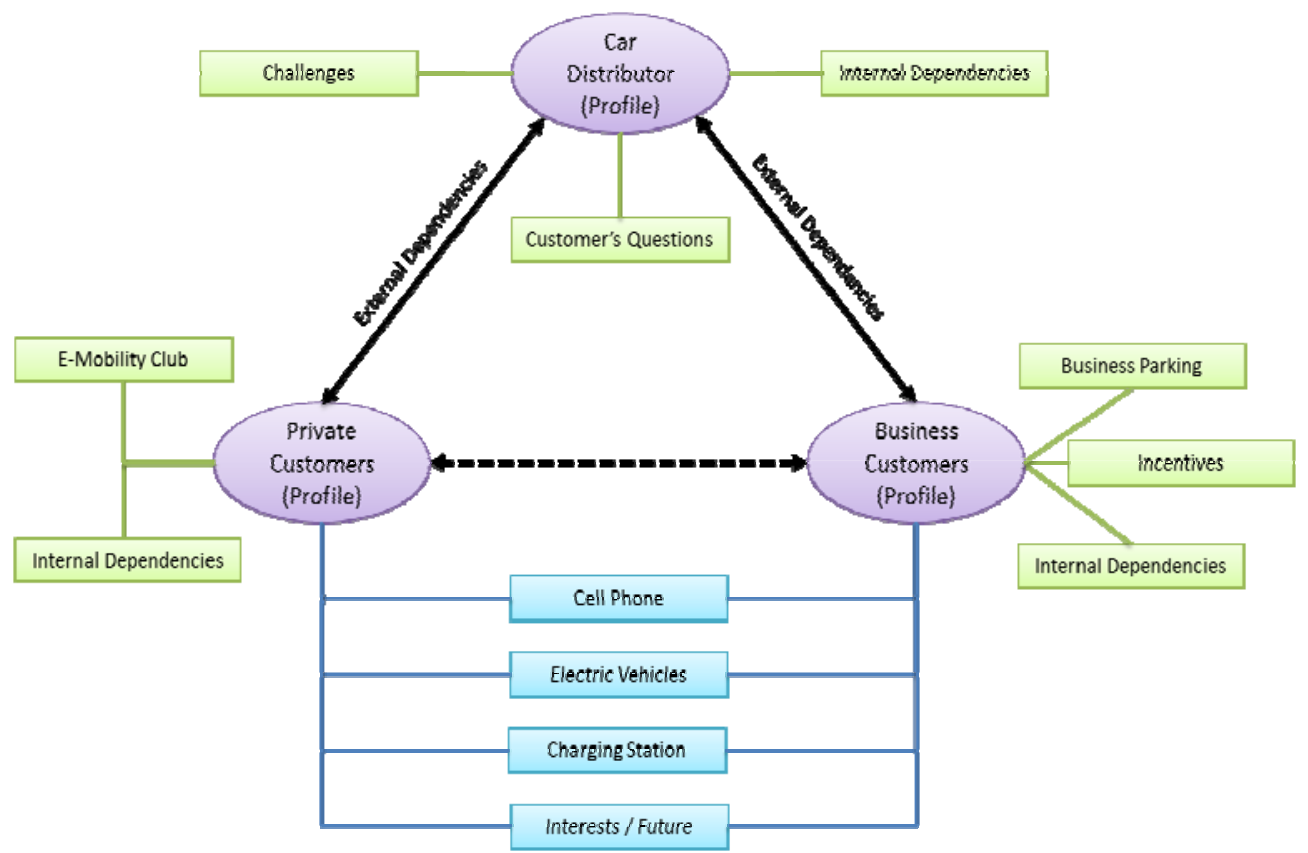

Fig. 1. Model of the analysis.

The model is composed of the three different questionnaires. Two of the three are strongly interlinked; the questionnaires for private and business customers share several identical question groups, highlighted in blue. The questionnaire for car distributors is not directly linked to the other two. The green boxes are interdependent question groups within one questionnaire.

\subsection{Automobile distributors}

Table 3 shows that more than $64 \%$ of the automobile distributors sell or plan to sell vehicle brands which have EV in their portfolio. Nearly $68 \%$ of the distributors have already invested or will invest in infrastructure for EV maintenance.

Table 3. Automobile distributor profile.

\begin{tabular}{|l|l|l|l|}
\hline & Already & Near future & No plans \\
\hline Electric Brand Coverage & 48.39 & 16.13 & 35.48 \\
\hline Investments & 29.03 & 38.71 & 32.26 \\
\hline
\end{tabular}

This can be understood as a very strong interest in EV from the distributor's point of view. Considering the customers of the automobile distributors, we determine that there is a difference between their interest in and the demand for EV, as shown in Fig. 2. 


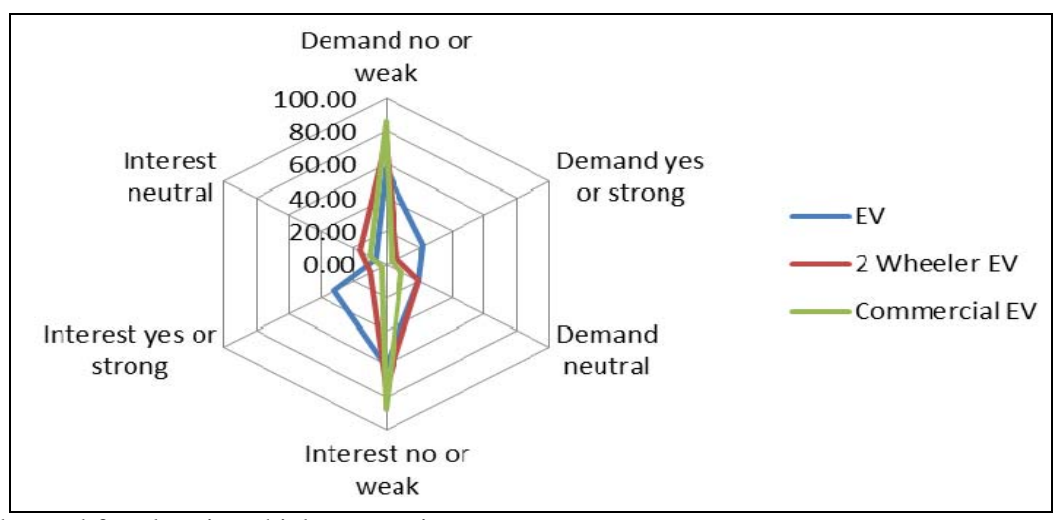

Fig. 2. Interest in and demand for electric vehicle categories.

Considering the customers of the automobile distributors and their sentiments towards EV we can see that major parts of the customers have weak or no interest and demand for one of the EV categories (cf. Fig. 2). Just for EV alone, we have an interest of over $30 \%$, yet a demand that is $10 \%$ less. This may be due to the fact that nearly $84 \%$ of the distributors see a major challenge in the cruising range provided through the battery, while more than two-thirds find the price to be the second major challenge.

\subsection{Private and business customers}

Males dominate the private customers' profile since only $21.83 \%$ of females responded (male: 78.17\%). More than three-fourths of the participants are between ages 25 and 55 (79.18\%), and they are equally distributed between the German and French speaking parts of Switzerland. Nearly $75 \%$ of the private participants have graduated from high school, technical college or university, and more than $60 \%$ have a yearly income higher than 60’000 CHF. On average, their travel to work amounts to $28.42 \mathrm{~km}$ per day.

It is not surprising that the intention to buy or not to buy an EV is related to income. On the other hand, our survey showed that the interest in EV does not generally depend on the participant's education.

The business customers profile is dominated by small-sized companies (75.76\%), followed by large companies (21.21\%), and just a few medium sized companies (3.03\%). More than $22 \%$ of the business participants were consultants, with nearly $20 \%$ coming from the industry sector, and nearly $10 \%$ belonging to public administration and the energy sectors.

In terms of the charging of $\mathrm{EV}$, it is important to know that nearly $85 \%$ of the business customers have their own parking garages and/or parking lots.

We know that state subsidies can generally force interest in certain questions. This is also true in the field of EV. For both private as well as business customers, subsidies will strongly influence the decision or at least the intention to buy some kind of EV (cf. Fig. 3).

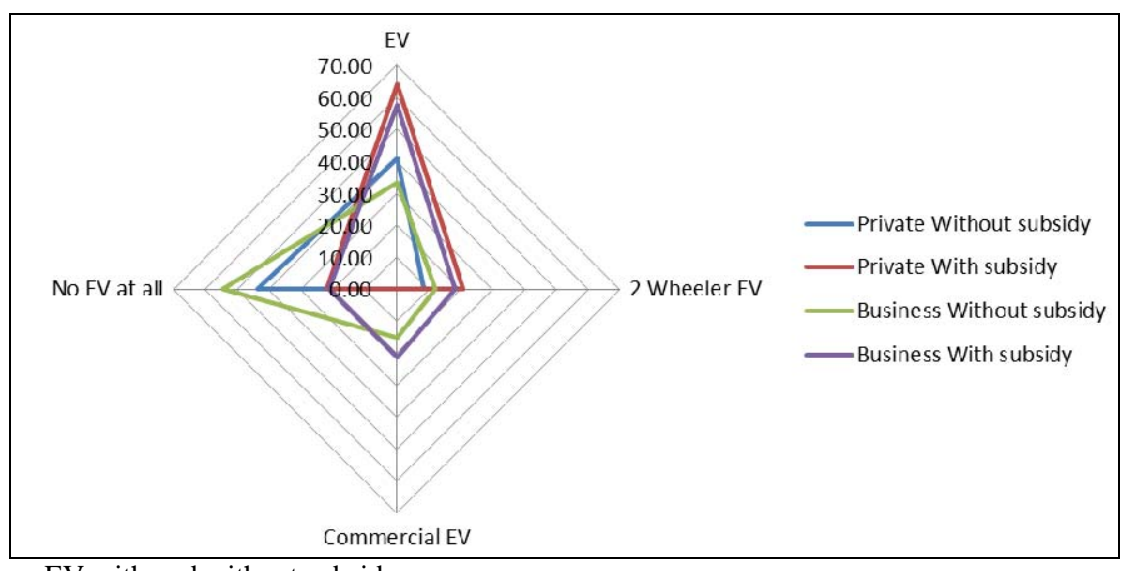

Fig. 3. Intention to buy EV with and without subsidy. 


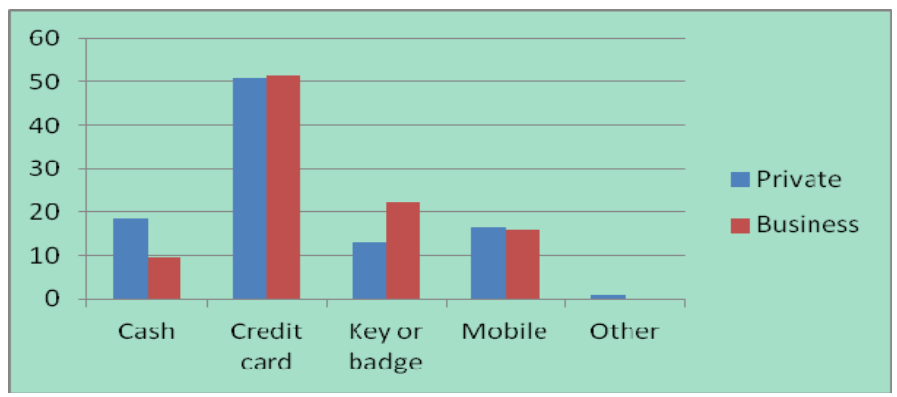

Fig. 4. Desired payment methods.

\subsection{Charging}

Potential customers expect that batteries are going to be recharged between three and four hours. This is due to their day-to-day routine, i.e., it corresponds to their work schedule. Obviously, the more the vehicle is used, the faster the recharge process must be.

In terms of the private sector, we can identify the desire for two major recharge places: at home and at work. Business customers have similar desires, except that charging stations at the enterprise are more important than charging stations at the employee's home.

Considering the requested methods of payment, there is a clear trend towards the use of credit cards (cf. Fig. 4). $16.50 \%$ would like to use a mobile phone for payment. This portion is expected to rise in case corresponding terminals are available. This assumption is based on the fact that $98.48 \%$ of the private customers and $78.79 \%$ of the business customers own mobile phones.

\section{Recommendations and Risks}

The overall quintessence of the analysis is that electric vehicles have a strong future in the eyes of the majority. The participants also believe that electric vehicles are more environmentally friendly than combustion engines. These are the main findings. To provide a more detailed picture, the results are summarized below.

- People are interested in politics and even more in environmental issues, which proves that the general interest in $\mathrm{EV}$ is evident.

- The actual demand for EV is rather low. This does not mean that people are not interested; according to the results of all the questionnaires, people do have a healthy interest in the topic.

- The data shows that private and business customers were buying EV with equal frequency but for different reasons.

- Car distributors and potential customers are well aware of challenges such as the battery range, the high initial price of EV, and the question of how to cover the additional electric current demand. According to car distributors, it will be hard to sell EV as long as these issues remain unsolved.

- The more the people are demanding and asking about EV, the more the distributors and garages are willing to invest. However, people have the feeling that not enough distributors/garages for EV currently exist. That means either the distributors or the customers must transcend the scope and go a step further in order to ignite the market.

- People living in the countryside are more likely to buy EV than people living in the city.

- People with a higher income are more likely to buy EV.

- About half of the business customers believe that EV could fulfill the entire needed requirement.

- Most companies have parking lots and a few even have parking garages where electric charging stations could be built in the future.

- Those charging stations could be optimally used since over $42 \%$ of the businesses offer the parking lots to external people as well.

- The two strongest incentives for people to buy EV are subsidies and a cost-performance ratio similar 
to combustion engine vehicles.

- The most requested methods of payment are credit cards and mobile phones.

The average expected kilometers that an EV should drive is $225 \mathrm{~km}$ per car, and $80 \mathrm{~km}$ per twowheeler when the battery is fully charged. Those numbers are much higher than what people travel on average per day. From this perspective, the range of EV is perfectly adequate. The expected distance is a desire rather than a strict requirement. This is not so with the price; people are definitely not willing to pay more for an EV than they do for a similar combustion vehicle. $80 \%$ of the respondents were saying that the technology is simply not fully developed yet. It is also almost contradictory that they should think in such a way, since most private customers would like to buy EV due to technical reasons and for the environment. Business customers would purchase EV primarily for prestige and image reasons. If the government would subsidize EV, both businesses and private customers would change their attitudes and a higher percentage of people would consider buying EV.

To summarize the main finding of the project, it is fundamental to discuss the electric charging stations. According to respondents, a charging station should be built every $16 \mathrm{~km}$ in order to have an optimal infrastructure. However, a huge majority of the participants also state that they would mostly recharge their vehicles at work or at home. This is due to the long charging times. People do not want to wait that long at a public place. On average, the EV should be fully recharged in $3 \mathrm{~h} 20 \mathrm{~min}$. Most participants state that the additional demand for electric current should be covered by solar, wind, and hydroelectric power. On average, $17 \%$ still think that atomic plants are needed.

\section{Acknowledgements}

The authors would like to thank the partners of the ePark project (http://epark.eia-fr.ch) for their support: Groupe E SA, iimt - University of Fribourg, Innovation Program of Canton of Fribourg, Cantonal Bank of Fribourg, Softcom Technologies AG, Swisscom SA, Touring Club Schweiz, University of Applied Sciences and Arts Western Switzerland.

\section{References}

[1] Graham JD, Messer NM, Hartmann D, Lane BW, Carley S, Crookham C. (2011). Plug-in electric vehicles: a practical plan for progress. [Online]. Available: http://works.bepress.com/bradleywlane/10

[2] Grunwald A. Sustainability assessment of technologies - an integrative approach. In: Ghenai C, editor. Sustainable Development - Energy, Engineering and Technologies - Manufacturing and Environment, Rijeka: InTech Europe; 2012:35-62.

[3] Hennebert J, Schmoutz A, Baudin S, Zambon L, Delley A. (2012). Le projet ePark - Solutions technologiques pour la gestion des véhicules électriques et de leur charge. [Online]. Available: http://www.bulletin-online.ch/uploads/media/1204_Seite_034036.pdf

[4] Eidgenossenschaft S, Bundesamt für Statistik. Strassenfahrzeugbestand nach fahrzeuggruppen. [Online]. Available: http://www.bfs.admin.ch/bfs/portal/de/index/themen/11/03/blank/key/fahrzeuge_strasse/bestand.html

[5] Eidgenossenschaft S. Bundesamt für Statistik. Bevölkerung - die wichtigsten Kennzahlen. [Online]. Available: http://www.bfs.admin.ch/bfs/portal/de/index/themen/01/01/key.html

[6] Eidgenossenschaft S, Bundesamt für Statistik. Das Budget der privaten Haushalte. Bern: BfS-Medienmitteilung; 2008.

[7] Eidgenossenschaft S, Bundesamt für Statistik. Marktwirtschaftliche unternehmen und beschäftigte nach grössenklassen.. [Online]. Available: http://www.bfs.admin.ch/bfs/portal/de/index/themen/06/02/blank/key/01/groesse.html

[8] Auto-schweiz. [Online]. Available: http://www.auto-schweiz.ch/

[9] Auto gewerbe verband Schweiz. [Online]. Available: http://www.agvs.ch/Daten-und-Fakten.232.0.html

[10] Aaker DA, Kumar V, Day GS. Marketing Research. 8th ed. Hoboken: John Wiley \& Sons; 2004.

[11] Neuhaus R. Electric Park System. Fribourg: iimt University Press; 2011.

[12] LimeSurvey. Open source survey application. [Online]. Available: http://www.limesurvey.org/

[13] Bühl A. SPSS 20: Einführung in Die Moderne Datenanalyse. 13th ed. Munich: Pearson; 2011. 